\title{
Breeding Alfalfa (Medicago sativa L.) in Mixture with Grasses
}

\author{
Christoph Grieder ${ }^{1, *(D)}$, Katharina Kempf ${ }^{1,2}$ and Franz Xaver Schubiger ${ }^{1}$ \\ 1 Group of Fodder Crop Breeding, Agroscope, 8046 Zurich, Switzerland; katharina.kempf@ufarevue.ch (K.K.); \\ schubiger@pflanzenkrankheiten.ch (F.X.S.) \\ 2 UFA-Revue, 8401 Winterthur, Switzerland \\ * Correspondence: christoph.grieder@agroscope.admin.ch; Tel.: +41-58-468-76-67
}

Citation: Grieder, C.; Kempf, K.; Schubiger, F.X. Breeding Alfalfa (Medicago sativa L.) in Mixture with Grasses. Sustainability 2021, 13, 8929. https://doi.org/10.3390/su13168929

Academic Editors: Monika Messmer, Vladimir Meglič and

Ferdinando Branca

Received: 27 June 2021

Accepted: 5 August 2021

Published: 10 August 2021

Publisher's Note: MDPI stays neutral with regard to jurisdictional claims in published maps and institutional affiliations.

Copyright: (c) 2021 by the authors. Licensee MDPI, Basel, Switzerland. This article is an open access article distributed under the terms and conditions of the Creative Commons Attribution (CC BY) license (https:// creativecommons.org/licenses/by/ $4.0 /)$.

\begin{abstract}
Cultivation of forage mixtures offers several advantages over monocultures, but forage legumes like alfalfa (Medicago sativa L.) are mostly bred in pure stands. Our goal was to assess the extent of accession-by-cultivation system interaction when alfalfa plants are grown in pure stands or in an easily adaptable nursery system together with their companion grasses, thereby determining the system most suitable for selection in mixture. Spaced plants of 50 alfalfa accessions were grown on bare soil as control treatment (CONV), in a sown sward of short growing lawn cultivars of tall fescue (Festuca arundinacea Schreb.) and red fescue (F. rubra L.) (LAWN), and in a sown sward of taller forage cultivars of the same species (FORA). Accession-by-cultivation system interaction variances were large for growth habit but small for vigor. Phenotypic correlation coefficients $\left(r_{p}\right)$ among the cultivation systems were high for vigor, whereby LAWN was somewhat more predictive for FORA $\left(r_{p}, F O R A-L A W N=0.83\right)$ than CONV $\left(r_{p}, F O R A-C O N V=0.77\right)$. Observed accession-by-genotype interactions can be used pro or contra necessity for selection in mixture. However, the LAWN cultivation system might be a good compromise for practical breeding, allowing to account for given competition effects among species and to easily assess traits in the nursery.
\end{abstract}

Keywords: mixed cropping; interaction; nursery

\section{Introduction}

Due to positive interactions among grass and legume species, their cultivation in mixture offers higher forage yield potential compared to their monocultures [1]. Under conditions of limited nitrogen $(\mathrm{N})$ availability, as often encountered under conditions of organic agriculture with no mineral fertilization, transfer of symbiotically fixed $\mathrm{N}$ from legumes to grasses is a key mechanism for this positive interaction [2] and was shown to contribute substantially to total nitrogen yield in clover-ryegrass mixtures [3]. Other synergistic effects like niche complementarity for below (e.g., water, nutrients) and above ground (e.g., light) resources may also play an important role [4]. Furthermore, mixtures offer higher resilience against unpredictable climatic conditions and weed infestation, while legumes increase the nutritive value and voluntary intake by animals [5]. Hence, multispecies sown grasslands play an important role to foster more sustainable production of forages and are an important tool for organic agriculture.

Forage legume species are typically bred as synthetic cultivars that represent a population of genetically heterogeneous individuals, reproducing by open pollination among them. During the early breeding process, single spaced plants (at a distance so individual plants can be distinguished from each other, depending on plant size and breeder's preference ranging from 30 to $100 \mathrm{~cm}$ ) are grown in the breeding nursery and are evaluated for several traits (vigor, disease resistance, quality, etc.). The 5-30 best plants are then clonally reproduced and allowed to flower in a so-called polycross to allow panmictic recombination and to produce seed of a new potential cultivar. Since the beginning of breeding activities for forages, the selection of cultivars for use in grasslands has mostly focused on increased performance in pure stands [6]. This means that spaced plants grow 
in a nursery without their future companion grasses. Furthermore, potential cultivars are tested for performance in monoculture to select the best candidates for cultivar registration. Therefore, it may happen that a cultivar is distributed to farmers in a mixture without ever having been tested for performance in a mixture before.

The growth of a species or cultivar in pure stand is likely to be different compared to a multispecies mixture [7], resulting from complex interactions with neighboring plants. To examine the extent of such possible interaction effects and to test if cultivars selected for good performance in pure stands also show high performance in mixture, empirical experiments can be conducted. For example, a number of cultivars or genotypes of species A can be grown in pure stands and in binary mixtures with different cultivars of species B (or with several other species B-N). If, for example, focus is on selection of a given forage legume species, the forage legume cultivars or genotypes have to be tested in binary mixtures with several different cultivars of a given grass species (or different grass species) using a factorial design. Thereby, it will be possible to determine the general mixing ability (GMA), i.e., the average performance of a legume cultivar in mixture over all mixing partners, and the specific mixing ability (SMA), i.e., the deviation of one specific legumegrass combination from what would be expected from GMA. A cheap and easy way to test for GMA would be to test legume cultivars in mixture with a broad tester population that could, for example, consist of several grass species or cultivars sown together [8]. In case of strong interactions between legumes and grasses, low correlations between performance in pure stand and in mixture (GMA) would result, demanding a specific selection for performance in mixtures. When doing specific selection for performance in mixture, a black-box or a functional approach can be used [9]. The black box approach traditionally involves testing the target species in mixture to identify candidates with a good GMA. Such candidates with good GMA would be preferred as they could then be broadly applied to improve performance of mixtures. However, this approach also assumes that GMA effects are larger than SMA effects and that improving performance of the target species will also improve performance of the mixture [9]. The functional approach is based on the concept of niche/resource complementarity and selection based on traits related to resource use complementarity, called interaction traits, has been suggested [10]. However, this approach requires prior knowledge on the relevant traits and their optimal expression level and can be expected to be less effective if the number of interaction traits is large.

Extensive literature reviews summarizing current theories and experimental data of selecting forages for mixture have recently been published $[9,11,12]$. Data assessed in previous experiments so far has led to different conclusions about the importance of breeding/testing in mixtures. Based on experiences from cultivar testing trials with different forage crops, Charles and Lehmann [13] conclude that a good cultivar in monoculture will also show good performance in mixture. In comparison, correlations between pure stands and mixtures with grasses for white clover (Trifolium repens L.) were found to be low to moderate [14-16], and some authors [8,14] conclude that direct selection of white clover in mixture would be more effective than selection in pure stands. For alfalfa, generally positive, moderate to strong correlations between performance in pure stand and mixture with grasses were observed in previous studies [17-19]. However, especially when looking only at the few top performing genotypes (the ones most relevant in a breeding program), these correlations might be lower and changes in ranking of genotypes can occur [19], again making direct selection in the mixture promising.

Due to climate change, water limitation of crops during summer drought spells is predicted to increase in frequency for humid Central European regions like Switzerland [20]. Therefore, the importance of forage mixtures with drought tolerant legume species such as alfalfa is expected to increase, whereby typical mixing partners would be drought tolerant grasses like tall fescue (Festuca arundinacea Schreb.), red fescue (F. rubra L.), or orchard grass (Dactylis glomerata L.) [21]. Adapting alfalfa to the conditions encountered in the mixture early in the breeding process would be desired and most straightforward. In order to select the parental plants for good performance in mixture, the corresponding selection pressure 
should already be applied early in the breeding process in the spaced plant nursery field. In this study, we evaluated the effect of selection of spaced $(45 \mathrm{~cm})$ alfalfa plants that are grown on bare soil (monoculture) versus within a densely sown sward of tall fescue and red fescue (mixture). Such a simple spaced plant breeding nursery setup could easily be implemented in a breeding program. Thereby, our aims were (1) to assess the extent of accession-by-cultivation system interaction and (2) to determine a suitable selection system for selection in mixture.

\section{Materials and Methods}

This study is based on 50 different accessions of alfalfa, of which 25 are landraces, ecotypes, or old cultivars (accession 1 to 25 ) and 25 are currently registered cultivars (accession 26-50, Table S1). In June 2017, pregerminated seeds were sown in the greenhouse and in August, plantlets were transplanted to the field at the Agroscope Reckenholz research station in Zurich, Switzerland $\left(47^{\circ} 25^{\prime} 41^{\prime \prime} \mathrm{N} 8^{\circ} 31^{\prime} 01^{\prime \prime} \mathrm{E}\right)$. The spaced alfalfa plants were grown in three cultivation systems: alfalfa plants on bare soil (CONV), alfalfa plants in a sward of shallow growing lawn type grasses (LAWN), and alfalfa plants in a sward of tall growing forage type grasses (FORA) (Figure 1). For the CONV cultivation system, a pendimethalin containing pre-emergence herbicide (Stomp Aqua, BASF, Ludwigshafen, Germany) was applied twice, after planting in 2017 and in spring 2018, to stop weeds from germinating and keep a bare soil. For the LAWN and FORA cultivation systems, seeds of red fescue and tall fescue were sown immediately before planting at a rate of 1 and $1.5 \mathrm{~g} \mathrm{~m}^{-2}$, respectively. The used cultivars were red fescue cv. Jasperina and tall fescue cv. Asterix for the LAWN and red fescue cv. Reverent and tall fescue cv. Belfine for the FORA cultivation systems. In addition to red and tall fescue, Kentucky bluegrass (Poa pratensis L.) cv. Connie (lawn type) was sown in LAWN and FORA plots as this species can fill possible gaps in the sward in case some plants of the fescues disappear.
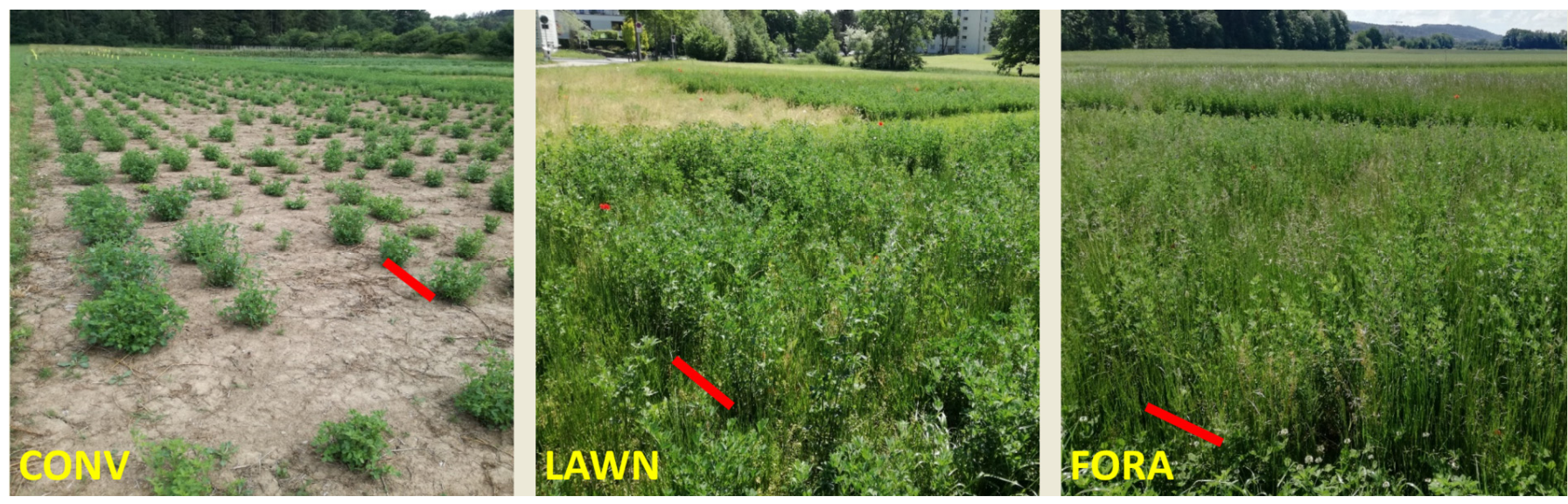

Figure 1. Spaced alfalfa plants in the CONV (bare soil), LAWN (sward with lawn-type grasses), and FORA (sward with forage-type grasses) cultivation systems during the first growth of the second year. Red scale bars indicate the planting distance within rows of $45 \mathrm{~cm}$.

For each of the 50 accessions, 30 plants were grown per cultivation system, resulting in 4500 spaced plants in total. Plants of the CONV cultivation system were grown on a conventionally managed field and plants of the LAWN and FORA cultivation systems on an adjacent organically managed field. A typical breeding nursery design was used, with ten alfalfa plants of the same accession being planted in a row. Planting distance was $45 \mathrm{~cm}$ within and $50 \mathrm{~cm}$ between rows. On the conventionally managed field, three blocks of 50 rows (1 row per accession) were formed, all of them receiving the CONV treatment. On the organically managed field, six blocks of 50 rows were formed, alternately receiving the LAWN and the FORA treatments. This resulted in a split-plot like design with blocks 
and rows representing two different strata of main-plots. See Figure S1 for a graphical illustration of the design.

The trial lasted until 2019 and traits were recorded on a single plant basis before each cut (one cut in autumn 2017, four cuts in 2018, one cut in May 2019). Plant vigor was rated on a scale from $1=$ high to $9=$ low and served as a proxy for plant biomass that was not additionally assessed. Crown and root rot caused by Sclerotinia trifoliorum Erikss. and downy mildew caused by Peronospora trifoliorum de Bary were rated upon occurrence from $1=$ no symptoms to $9=$ highly infected. Additional traits assessed visually were growth habit $(1=$ erect, $9=$ prostrate $)$, stem diameter $(1=$ thin, $9=$ thick $)$, and leaf-to-stem ratio (1 = high leaf proportion, 9 = low leaf proportion).

Analysis of variance (ANOVA) was computed using mixed models. The following model was employed:

$$
y_{i j m n}=\mu+g_{i}+e_{j}+g e_{i j}+b_{m}+r_{n}+\epsilon_{i j m n}
$$

where, $y_{i j m n}$ represents the observation for trait $y$ on a single plant basis, $\mu$ denotes the overall mean, $g_{i}$ is the effect of accession $\mathrm{i}, e_{j}$ the effect of cultivation system $\mathrm{j}, g e_{i j}$ the interaction between accession $\mathrm{i}$ and cultivation system $\mathrm{j}, b_{m}$ the effect of block $\mathrm{m}, r_{n}$ the effect of row $\mathrm{n}$, and $\varepsilon_{i j m n}$ is the residual error. In a first model, effect $r_{n}$ was considered as random while all other effects were considered as fixed. To estimate respective variance components, $g_{i}$ and $g e_{i j}$ were additionally considered as random in a second model. Phenotypic correlations between the CONV and LAWN $\left(r_{p}, C O N-L A W N\right)$, the CONV and FORA $\left(r_{p}\right.$, CON-FORA $)$, as well as the FORA and LAWN $\left(r_{p}\right.$, FORA-LAWN $)$ cultivation systems were calculated as Pearson's correlation coefficients based on accession means per cultivation systems $(n=50)$. All calculations were performed within the R-environment v. 3.5 [22]. Mixed model analyses were performed using the package lme4 [23].

\section{Results}

\subsection{Variance Explained by Accession, Cultivation System and Their Interaction}

Variance components due to accession $\left(\sigma_{g}^{2}\right)$, accession-by-cultivation system interaction $\left(\sigma_{g e}^{2}\right)$, and residual error $\left(\sigma_{\epsilon}^{2}\right)$ strongly depended on the respective traits. For vigor measured over three years, $\sigma_{g}^{2}$ was largest for vigor as assessed in the first year (vigor_2017_1) with a value of 0.46 relative to error variance (Table 1). For vigor assessed in 2018 and 2019, estimates of $\sigma_{g}^{2}$ were all similar, with values relative to error variance ranging from 0.18 to 0.3 . Accession-by-cultivation system interaction variance $\left(\sigma_{g e}^{2}\right)$ was comparably small for all vigor traits, with values relative to $\sigma_{\epsilon}^{2}$ ranging between 0 and 0.05 . This indicates that accessions grow (or have been rated) similarly among the cultivation systems for plant vigor.

Among disease traits, the occurrence of sclerotinia crown and root rot (sclerotinia_2018_1a/b, sclerotinia_2019_1) revealed a low genetic control as indicated by very low $\sigma_{g}^{2}(0.00-0.01$ relative to $\left.\sigma_{\epsilon}^{2}\right)$ and also low $\sigma_{g e}^{2}\left(0.02-0.04\right.$ relative to $\left.\sigma_{\epsilon}^{2}\right)$. In contrast, $\sigma_{g}^{2}$ was distinctively higher for occurrence of downy mildew (peronospora_2018_1), indicating a strong genetic control. The estimate of $\sigma_{g e}^{2}$ was zero, indicating very low to no interaction of accession with cultivation system, i.e., an identical judgment of accessions independent of the cultivation system (Figure 2). 
Table 1. Estimates of variance components due to accession $\left(\sigma_{g}^{2}\right)$, accession-by-cultivation system interaction $\left(\sigma_{g e}^{2}\right)$, and residual error $\left(\sigma_{\epsilon}^{2}\right)$. Numbers in brackets give the extent of a variance component relative to the error variance.

\begin{tabular}{|c|c|c|c|c|c|c|}
\hline \multirow[b]{2}{*}{ Trait $^{1}$} & \multicolumn{6}{|c|}{ Variance Components } \\
\hline & \multicolumn{2}{|c|}{$\sigma_{g}^{2}$} & \multicolumn{2}{|c|}{$\sigma_{g e}^{2}$} & \multicolumn{2}{|c|}{$\sigma_{\epsilon}^{2}$} \\
\hline & \multicolumn{6}{|c|}{ Vigor traits } \\
\hline vigor_2017_1 & 0.83 & $(0.46)$ & 0.09 & $(0.05)$ & 1.79 & $(1.00)$ \\
\hline vigor_2018_1 & 0.59 & $(0.18)$ & 0.06 & $(0.02)$ & 3.24 & (1.00) \\
\hline vigor_2018_2 & 0.72 & $(0.28)$ & 0.01 & $(0.00)$ & 2.59 & (1.00) \\
\hline vigor_2018_3 & 0.62 & $(0.25)$ & 0.04 & $(0.02)$ & 2.49 & $(1.00)$ \\
\hline vigor_2018_4 & 0.69 & $(0.30)$ & 0.06 & $(0.03)$ & 2.28 & $(1.00)$ \\
\hline \multirow[t]{2}{*}{ vigor_2019_1 } & 0.63 & $(0.24)$ & 0.07 & $(0.03)$ & 2.60 & (1.00) \\
\hline & \multicolumn{6}{|c|}{ Disease occurrence traits } \\
\hline sclerotinia_2018_1a & 0.005 & $(0.00)$ & 0.089 & $(0.04)$ & 2.23 & $(1.00)$ \\
\hline sclerotinia_2018_1b & 0.018 & $(0.01)$ & 0.092 & $(0.03)$ & 2.86 & (1.00) \\
\hline sclerotinia_2019_1 & 0.000 & $(0.00)$ & 0.006 & $(0.02)$ & 0.32 & (1.00) \\
\hline \multirow{2}{*}{ peronospora_2018_1 } & 0.605 & $(0.24)$ & 0.000 & $(0.00)$ & 2.51 & (1.00) \\
\hline & \multicolumn{6}{|c|}{ Morphological traits } \\
\hline habit_2018_1 & 0.39 & $(0.42)$ & 0.28 & $(0.30)$ & 0.95 & $(1.00)$ \\
\hline habit_2018_2 & 0.29 & $(0.31)$ & 0.09 & $(0.10)$ & 0.95 & $(1.00)$ \\
\hline $\begin{array}{c}\text { stem- } \\
\text { diameter_2018_1 }\end{array}$ & 0.45 & $(0.19)$ & 0.02 & $(0.01)$ & 2.33 & $(1.00)$ \\
\hline $\begin{array}{l}\text { leaf-stem- } \\
\text { ratio_2018_1 }\end{array}$ & 0.11 & $(0.10)$ & 0.00 & $(0.00)$ & 1.19 & $(1.00)$ \\
\hline $\begin{array}{l}\text { leaf-stem- } \\
\text { ratio_2018_2 }\end{array}$ & 0.16 & $(0.11)$ & 0.01 & $(0.01)$ & 1.50 & $(1.00)$ \\
\hline
\end{tabular}

${ }^{1}$ First and second number after trait name indicate the year and growth at which data was recorded, respectively (i.e., vigor_2018_1 means vigor assessed in 2018, first cut). If a trait was assessed two times on the same growth, this is indicated by a letter following the trait (i.e., sclerotinia_2018_1a, sclerotinia_2018_1b).
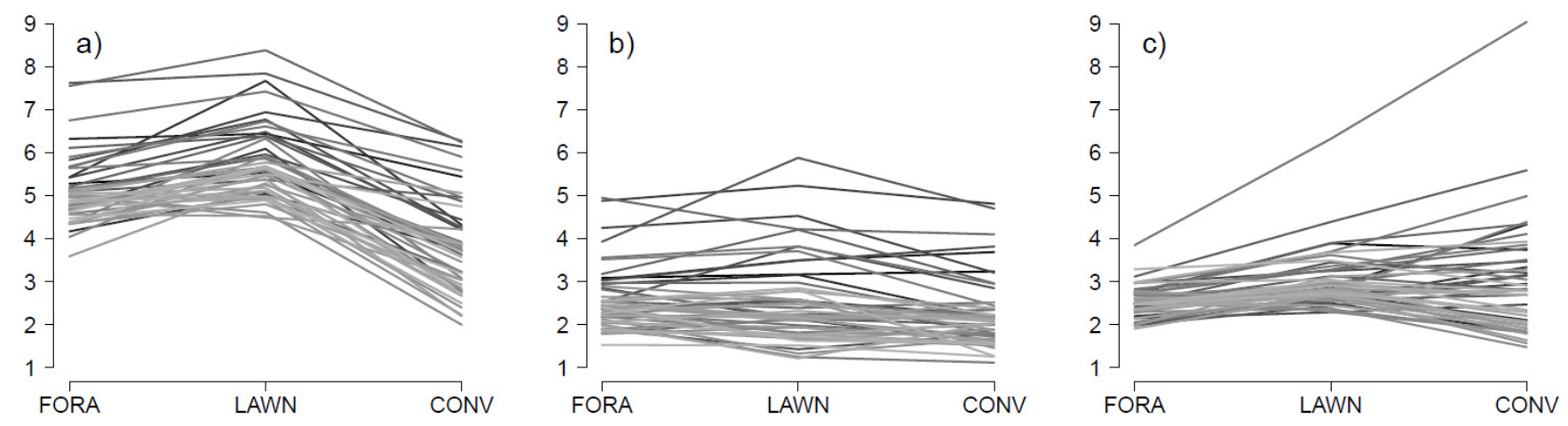

Figure 2. Interaction plot showing performance of spaced alfalfa plants (mean values per accession, denoted by different grey levels) in the FORA, LAWN, and CONV cultivation systems for (a) vigor assessed in first cut of second year (vigor_2018_1), (b) occurrence of downy mildew (peronospora_2018_1), and (c) growth habit assessed in first growth of second year (habit_2018_1).

Growth habit showed large $\sigma_{g}^{2}$ relative to $\sigma_{\epsilon}^{2}$ of 0.42 and 0.31 for the first and second cut in 2018, respectively, indicating substantial genetic control. Especially for the first cut of the 2018 season, when forage grasses among the alfalfa plants were growing tall and forming tillers, a large $\sigma_{g e}^{2}$ was observed for growth habit $\left(0.30\right.$ relative to $\left.\sigma_{\epsilon}^{2}\right)$. This value was highest among all traits assessed and indicates a different rating/growth of alfalfa plants among cultivation systems. For the other morphological traits, stem-diameter and leaf-stem-ratio, intermediate $\sigma_{g}^{2}\left(0.10-0.19\right.$ relative to $\left.\sigma_{\epsilon}^{2}\right)$ and very low $\sigma_{g e}^{2}(0.00-0.01$ relative to $\sigma_{\epsilon}^{2}$ ) were observed.

\subsection{Correlations among Cultivation Systems}

The patterns observed in the variance components were also reflected in the correlations among cultivation systems. Among the vigor traits that showed rather small 
accession-by-cultivation system interactions, strong correlations were observed, with $r_{p}$ ranging between 0.71 and 0.90 (Table 2). Averaging $r_{p}$ over all vigor traits, the strongest correlation was observed between the FORA and LAWN cultivation system $\left(r_{p}\right.$, FORA-LAWN $=0.83$ ), but only slightly lower values were observed between the LAWN and CONV $\left(r_{p}\right.$, LAWN-CONV $\left.=0.78\right)$ and between FORA and CONV $\left(r_{p}\right.$, FORA-CONV $\left.=0.77\right)$ cultivation systems. Examining each time point when vigor was assessed separately, weakest correlations were observed for the first cut of the second year (vigor_2018_1) with $r_{p}$ ranging between 0.74 and 0.76 . During this time, the companion grasses are forming tillers and (especially forage grasses) are growing strongest. Already in the subsequent cut (vigor_2018_2), when grasses do not form tillers and do not interfere with growth of alfalfa plants that much anymore, $r_{p}$ increased to $0.83-0.86$, indicating a higher congruency among cultivation systems. When reducing the phenotypic variation and looking only at the 15 accessions with the best average performance for vigor, correlation values dropped substantially to non-significant levels of 0.26 for $r_{p}$, FORA-LAWN, 0.13 for $r_{p}$, FORA-CONV, and 0.34 for $r_{p, L A W N-C O N V}$, (Table 2 values in brackets, Figure 3).

Table 2. Correlations among the three cultivation systems for different traits assessed on spaced alfalfa plants. Correlation coefficients are based on accession means per cultivation system $(n=50)$. For vigor traits, numbers in brackets give the correlation coefficients based on the 15 accessions that showed best performance on average over all vigor traits.

\begin{tabular}{cccc}
\hline & \multicolumn{3}{c}{$\mathbf{r}_{\mathbf{p}}$} \\
\cline { 2 - 4 } Trait 1 & FORA-LAWN & FORA-CONV & LAWN-CONV \\
vigor_2017_1 & $0.90^{* *}\left(0.83^{* *}\right)$ & $0.73^{* *}(0.44)$ & $0.74^{* *}(0.47)$ \\
vigor_2018_1 & $0.76^{* *}(-0.09)$ & $0.74^{* *}(0.01)$ & $0.75^{* *}\left(0.55^{*}\right)$ \\
vigor_2018_2 & $0.83^{* *}(0.23)$ & $0.85^{* *}\left(0.52^{*}\right)$ & $0.86^{* *}\left(0.56^{*}\right)$ \\
vigor_2018_3 & $0.82^{* *}(0.29)$ & $0.78^{* *}(0.06)$ & $0.80^{* *}\left(0.74^{* *}\right)$ \\
vigor_2018_4 & $0.84^{* *}(0.06)$ & $0.79^{* *}(-0.33)$ & $0.79^{* *}(-0.05)$ \\
vigor_2019_1 & $0.85^{* *}(0.24)$ & $0.74^{* *}(0.05)$ & $0.71^{* *}(-0.23)$ \\
Mean vigor & $0.83^{* *}(0.26)$ & $0.77^{* *}(0.13)$ & $0.78^{* *}(0.34)$ \\
sclerotinia_2018_1a & 0.16 & Disease occurrence traits & 0.06 \\
sclerotinia_2018_1b & $0.30^{*}$ & -0.05 & 0.17 \\
scletinia_2019_1a & -0.02 & -0.02 & -0.20 \\
peronospora_2018_1 & $0.86^{* *}$ & -0.07 & $0.86^{* *}$ \\
habit_2018_1 & $0.73^{* *}$ & $0.82^{* *}$ & $0.86^{* *}$ \\
habit_2018_2 & $0.77^{* *}$ & Morphological traits & $0.78^{* *}$ \\
stem- & $0.77^{* *}$ & $0.57^{* *}$ & $0.78^{* *}$ \\
diameter_2018_1 & & $0.72^{* *}$ & $0.49^{* *}$ \\
leaf-stem- & $0.53^{* *}$ & $0.80^{* *}$ & $0.44^{* *}$ \\
ratio_2018_1 & & & \\
leaf-stem- & $0.71^{* *}$ & $0.62^{* *}$ & \\
ratio_2018_2 & & & \\
\hline
\end{tabular}

${ }^{1}$ See Table 1 for nomenclature of traits; ${ }^{*}$ and ${ }^{* *}$ correlation significant at an $\alpha=0.05$ and 0.01 level, respectively. 

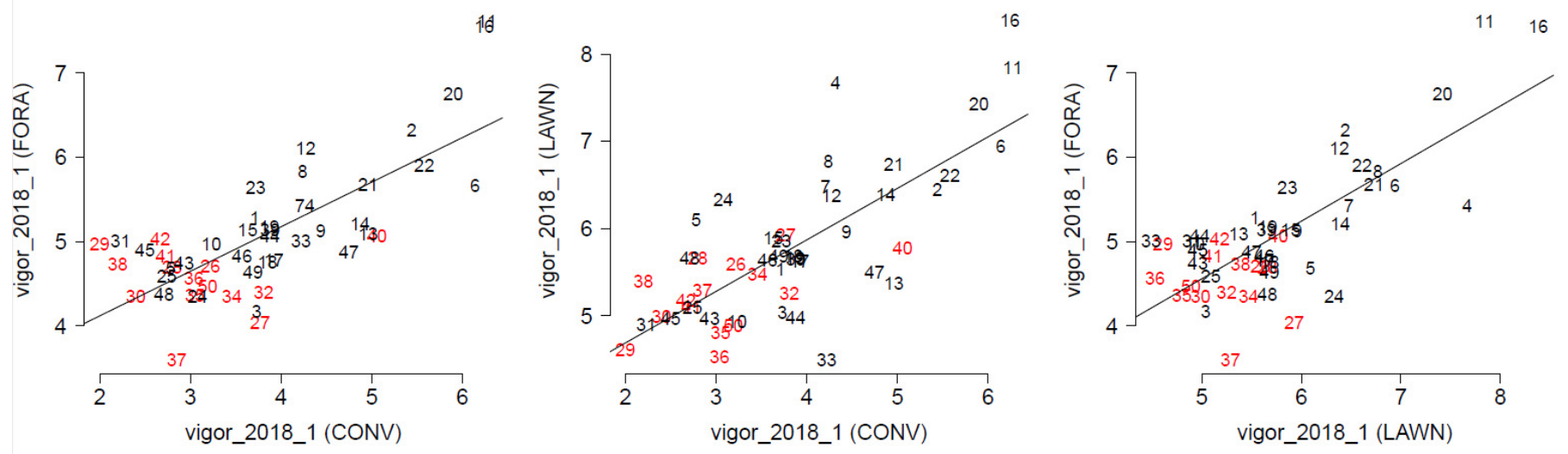

Figure 3. Biplot of plant vigor assessed in first cut of 2018 (vigor_2018_1) in the different cultivation systems. Numbers denote the accession number, the 15 accessions which showed highest vigor on average over all cuts assessed are displayed in red color.

The small genetic effects (low $\sigma_{g}^{2}$ and $\sigma_{g e}^{2}$ ) observed for occurrence of sclerotinia crown and root rot are reflected in the weak to very weak correlation among cultivation systems for this trait. Because phenotypic data was dominated by experimental error, $r_{p}$ ranged between -0.20 and 0.30 , being non-significant with the only exception of $r_{p}$, FORA-LAWN for sclerotinia assessed the second time in the first growth 2018. On the contrary, the strong genetic control (high $\sigma_{g}^{2}$ ) but rather low interaction between accession and cultivation system (low $\sigma_{g e}^{2}$ ) for occurrence of downy mildew led to strong correlations among all cultivation systems ( $r_{p}$ from 0.82 to 0.86 ). This indicates a congruent assessment of downy mildew occurrence independent of the cultivation system.

The large accession-by-cultivation system interaction observed for growth habit in the first cut (habit_2018_1) is reflected by the only moderate correlation between the FORA and CONV cultivation systems $\left(r_{p}\right.$, FORA-CONV $\left.=0.57\right)$. This means that growth habit of alfalfa plants was strongly influenced by tall growing grasses in the FORA cultivation system, leading to a different ranking compared to CONV (Figure 2). Influence of small growing lawn grasses on the growth habit of alfalfa plants was only limited, as reflected by the strong correlation between LAWN and CONV cultivation systems for this trait $\left(r_{p}, L A W N-C O N V=0.86\right)$. For the subsequent cut (habit_2018_2), the smaller $\sigma_{g e}^{2}$ compared to the first cut also resulted in a higher congruence among cultivation systems $\left(r_{p}\right.$ from 0.77 to 0.79 ). Correlations among cultivation systems were all moderately strong for stemdiameter. With the exception of $r_{p}, F O R A-C O N V$ that had a value of 0.80 , only moderate correlations $\left(r_{p}=0.44-0.71\right)$ among cultivation systems were observed for leaf-stem-ratio, a trait that is subjective in its assessment and only showed moderate genetic control.

\section{Discussion}

In this study, we could quantify the genotype-by-cultivation system interaction of alfalfa with its companion grasses. The simple breeding nursery layout with undersowing a diverse mixture of lawn or forage grasses could be easily implemented in any breeding program. It imitates the situation of a "broad tester" that allows estimation of the GMA effects [8], wherefore we assume that our results would be relevant for a broader range of grass mixing partners. We followed the black box approach and assume that the obtained results for alfalfa performance are relevant for the use in targeted mixtures, i.e., with drought tolerant grasses like tall fescue or orchard grass. 


\subsection{Will Different Cultivation Systems Lead to Different Selection Decisions?}

From CONV to LAWN to FORA cultivation systems, an increasing competition by the grass partner could be simulated. This increasing competition was supported by measurements of height of companion grasses after heading, which averaged $85 \mathrm{~cm}$ for the LAWN and $133 \mathrm{~cm}$ for the FORA cultivation systems (data not shown). Thereby, it was possible to evaluate if selection decisions, on the level of accessions, would be different or not. When looking at plant vigor, we observed generally strong correlations among the cultivation systems indicating that selection decisions would not largely differ. Because the situation faced by the alfalfa plants are most divergent between the CONV and the FORA cultivation systems (no competition vs. strong competition by vigorously growing forage grasses, respectively), the correlation for vigor was somewhat weaker between the FORA and CONV $\left(r_{p}=0.77\right)$ compared to the more similar FORA and LAWN cultivation systems $\left(r_{p}=0.83\right)$. Observed correlations are in agreement with results of a recent study [19], where authors reported a correlation coefficient of 0.84 between biomass of alfalfa genotypes grown in densely planted ( $7 \mathrm{~cm}$ spacing among plants) mini-plots in pure stand and in mixture with grasses. For plant vigor, correlation between monoculture (CONV) and mixture (FORA) of the extent as observed in our study could be used to argue pro and contra necessity to select in mixture. If the same selection intensities and heritabilities under FORA and CONV conditions are assumed, the relative efficiency (RE) of indirect selection in CONV to improve performance under FORA will be equal to the genetic correlation coefficient $\left(r_{g}\right)$ between the two systems [24]. With $r_{p, \text { FORA-CONV of } 0.77 \text { being }}$ a lower boundary of $r_{g}$,FORA-CONV, a minimum RE of 0.77 for indirect selection in CONV to improve performance under FORA can be expected, which is quite substantial. However, a $r_{p, F O R A-C O N V}$ of 0.77 also allows for certain changes in genotype ranking, which would be an argument pro selection in mixture.

From previous studies that examined the performance of alfalfa in pure stand and in mixture, some came to the conclusion that selecting alfalfa in mixture would be superior over selection in monoculture $[19,25,26]$, whereas others concluded that evaluation in monoculture would be sufficient due to similar ranking of genotypes [18,27]. In their study, Maamouri et al. [19] pointed out that despite general positive correlations, rank changes occurred for the top performing genotypes between pure and mixed stands, highlighting the need for direct selection in mixture. In our study, not only current elite germplasm (accession number 26-50), but also landraces and ecotypes from genebanks (accession number 1-25) were evaluated, thereby broadening the spectrum of phenotypic performance. In accordance to a previous study [19], the correlation values for vigor dropped down if only the top performing accessions are looked at (Table 2, Figure 3). Only looking at the 15 accessions with best average vigor, correlation coefficients dropped to non-significant levels. This might be partly related to the reduced statistical power due to the lower number of accessions (15 instead of 50). However, it also demonstrates that when working within a set of elite germplasm with reduced variation, genotype-by-cultivation system interactions might play a more important role and selection decisions, therefore, will be different among cultivation systems.

The two disease resistance traits assessed in our study, for which we relied on natural occurring infections, showed quite an opposite behavior. On one side, the occurrence of sclerotinia crown and root rot caused by S. trifoliorum was almost random, barely showing any accession or accession-by-cultivation system interaction variance. The very high residual variance in this data can be explained by the nature of infection of the pathogen. Primary infections of plants occur in autumn via ascospores, being produced from apothecia that grow out of sclerotia resting bodies in the soil [28]. In spring, when disease symptoms occur, the fungus has only limited ability to further disperse via growing mycelium. Uneven distribution of sclerotia in the field are probably the main drivers of an inhomogeneous disease pressure and missing genetic effect. On the other side, the large accession variance for occurrence of downy mildew caused by P. trifoliorum can be explained by a homogenous disease pressure, that also results from a fast reproduction 
cycle and secondary infections via sporangia in spring [28]. The inexistent accession-bycultivation system variance (Table 1) and strong correlations among cultivation systems (Table 2) highlight that the disease occurrence can be well assessed in all three different cultivation systems, that there is apparently no interaction with the companion grasses, and that selection can be performed in either one of the cultivation systems.

Among the morphological traits, growth habit at the first growth (habit_2018_1) showed the largest relative accession and at the same time accession-by-cultivation system variance. The latter can be mainly explained by a large interaction of alfalfa plants with the tall growing forage grasses of the FORA treatment, forcing prostrate growing alfalfa plants to a more erect growth. This has to be kept in mind when thinking of the DUS (distinctness, uniformity, stability) criteria for cultivar registration: growing plants in pure stands would be necessary to determine their true growth habit and to combine genotypes into a cultivar that meets the uniformity criteria. For the other morphological traits, i.e., stem diameter and leaf-stem-ratio, no clear statement can be given with regard to the rather small genotypic variance observed.

\subsection{What Plants to Select in What System for More Resilient Organic Systems?}

In our study with the CONV, LAWN, and FORA cultivation systems, where a sward of grasses has been sown among the spaced alfalfa plants, the focus of selection is only on alfalfa. According to the theory of the black-box approach, a basic assumption is that improving performance of the target species, i.e., alfalfa, will also improve performance of the mixture [9]. If this assumption is not fulfilled, selection of vigorous alfalfa plants in the mixture might potentially lead to overly dominant alfalfa, suppressing the grass species. A multispecies sward corresponds to the situation of a competition environment where both, yielding and competitive ability of each genotype, play a role: In the case where plants selected for high vigor in the mixture are only undercompensating the yield lost by other (grass) plants, yield of the sward might get reduced [29]. In addition, farmers are not only interested in the total yield of a mixture, but also in a balanced legume to grass ratio. If environmental conditions are in favor of alfalfa (e.g., no $\mathrm{N}$ fertilization, dry conditions), mixtures can be dominated by alfalfa and persistency of the grasses might be reduced [30,31]. Maamouri et al. [19], for example, hypothesize that selection of alfalfa genotypes exerting lower competition on grasses (e.g., via smaller leaves or more prostrate growth) might be more suitable for mixtures in order to keep a balance between alfalfa and legume proportions in the mixture. However, their study was conducted at a site (Lusignan, France) that exhibits a drier climate with less rainfall during summer compared to our study site that represents typical temperate Swiss conditions. It can be expected that the competitive ability of alfalfa against grasses is highly dependent on the climate and it remains to be determined whether the ideotype of alfalfa for mixtures would need to be different, e.g., more competitive, to obtain balanced mixtures over time. In order to answer this question in the future, we have made selections in the three different cultivation systems, combining genotypes of contrasting competitive ability into experimental populations. These will be tested in Switzerland (reference humid climate) and Romania (anticipated drier climate) in sown swards with their companion grasses to test if genotypes selected for a high or intermediate competitive ability will lead to high yielding and balanced mixtures.

In our study, the LAWN cultivation systems were mostly between the two other systems. Compared to CONV, the LAWN cultivation system was more predictive for the FORA cultivation system, and competitive situation for alfalfa plants in the FORA and LAWN cultivation system can be expected to be similar. This is in agreement with an earlier study that found no interaction between multiple alfalfa and two tall fescue (lawn type vs. forage type) genotypes in an experiment with densely planted microplots [31]. However, LAWN also showed good congruence with the CONV system, especially for morphological traits like growth habit. The LAWN cultivation system might, therefore, be a good compromise, being especially suitable for organically managed nurseries. Compared 
to CONV, LAWN allows to better account for competition effects (especially below ground, but also partly above ground), as indicated by higher correlations with FORA. Additionally, it offers an easier trial handling because only reduced weed control, either by spraying (conventionally managed) or hoeing (organically managed), is necessary after the grass sward is established. In this study, less time had to be spent for weed control in LAWN compared to CONV. Compared to FORA, data assessment is easier in LAWN due to better visibility of plants, especially during the first growth of the season, allowing for better assessment of morphological traits.

\section{Conclusions}

Thanks to their manifold advantages, multispecies legume-grass mixtures are an important tool to foster more resilient organic forage production systems and their importance will grow at a European level. With the increasing impact of climate change, the demand for drought tolerant mixtures is and will be increasing. Thereby, alfalfa is one of the predestinated species to close the gap of drought tolerant forage legumes also in regions where it was not that widely used so far. For organic production systems in these regions to profit the most in terms of resilience and productivity, a targeted development of cultivars adapted to the regional climate, mixed cropping, and organic cultivation is needed. Our results indicate that direct selection in mixture might be superior over selection in pure stands, whereby differential selections performed in the three cultivation systems can be used over the coming years to experimentally validate the potential selection gain.

The LAWN cultivation system seems to be a suitable option, as it allows a good assessment of genotypes' performances in mixture and demands only low weed control actions, making it easy for breeders to switch to organic nurseries. Additionally, the broad genetic diversity assessed in this study showed that the used accessions show potential as starting points for targeted breeding for mixtures.

Supplementary Materials: The following are available online at https: / www.mdpi.com/article/ 10.3390/su13168929/s1, Figure S1: Graphical illustration of experimental design, Table S1: List of alfalfa accessions used in the experiment.

Author Contributions: Conceptualization, C.G. and F.X.S.; methodology, C.G. and K.K.; software, C.G.; validation, K.K. and C.G.; formal analysis, C.G.; investigation, K.K. and C.G.; resources, C.G.; data curation, K.K. and C.G.; writing-original draft preparation, C.G.; writing-review and editing, C.G. and K.K.; visualization, C.G.; supervision, F.X.S.; project administration, F.X.S.; funding acquisition, F.X.S. and C.G. All authors have read and agreed to the published version of the manuscript.

Funding: This project received funding within the project LIVESEED from the European Union's Horizon 2020 research and innovation programme under grant agreement No 727230 and by the Swiss State Secretariat for Education, Research and Innovation (SERI) under contract number 17.00090. The information provided reflects the views of the authors. The Research Executive Agency or SERI are not responsible for any use that may be made of the information provided.

Institutional Review Board Statement: Not applicable.

Informed Consent Statement: Not applicable.

Data Availability Statement: The data presented in this study are openly available at zenodo.org (https: / / zenodo.org/record/5035280) (accessed on 25 June 2021).

Acknowledgments: The authors thank Peter Tanner and Daniel Schmid for technical support on the field trials as well as Michelle Nay and Roland Kölliker for proofreading of the manuscript.

Conflicts of Interest: The authors declare no conflict of interest. The funders had no role in the design of the study; in the collection, analyses, or interpretation of data; in the writing of the manuscript, or in the decision to publish the results. 


\section{References}

1. Nyfeler, D.; Huguenin-Elie, O.; Suter, M.; Frossard, E.; Lüscher, A. Grass-legume mixtures can yield more nitrogen than legume pure stands due to mutual stimulation of nitrogen uptake from symbiotic and non-symbiotic sources. Agric. Ecosyst. Environ. 2011, 140, 155-163. [CrossRef]

2. Fustec, J.; Lesuffleur, F.; Mahieu, S.; Cliquet, J.-B. Nitrogen rhizodeposition of legumes. A review. Agron. Sustain. Dev. 2010, 30, 57-66. [CrossRef]

3. Zanetti, S.; Hartwig, U.A.; van Kessel, C.; Lüscher, A.; Hebeisen, T.; Frehner, M.; Fischer, B.U.; Hendrey, G.R.; Blum, H.; Nösberger, J. Does nitrogen nutrition restrict the $\mathrm{CO}_{2}$ response of fertile grassland lacking legumes? Oecologia 1997, 112, 17-25. [CrossRef]

4. Finn, J.A.; Kirwan, L.; Connolly, J.; Sebastià, M.T.; Helgadottir, A.; Baadshaug, O.H.; Bélanger, G.; Black, A.; Brophy, C.; Collins, R.P.; et al. Ecosystem function enhanced by combining four functional types of plant species in intensively managed grassland mixtures: A 3-year continental-scale field experiment. J. Appl. Ecol. 2013, 50, 365-375. [CrossRef]

5. Lüscher, A.; Mueller-Harvey, I.; Soussana, J.F.; Rees, R.M.; Peyraud, J.L. Potential of legume-based grassland-livestock systems in Europe: A review. Grass Forage Sci. 2014, 69, 206-228. [CrossRef] [PubMed]

6. Sampoux, J.P.; Baudouin, P.; Bayle, B.; Béguier, V.; Bourdon, P.; Chosson, J.F.; Deneufbourg, F.; Galbrun, C.; Ghesquière, M.; Noël, D.; et al. Breeding perennial grasses for forage usage: An experimental assessment of trait changes in diploid perennial ryegrass (Lolium perenne L.) cultivars released in the last four decades. Field Crop. Res. 2011, 123, 117-129. [CrossRef]

7. Hill, J. Breeding components for mixture performance. Euphytica 1996, 92, 135-138. [CrossRef]

8. Annicchiarico, P. Breeding white clover for increased ability to compete with associated grasses. J. Agric. Sci. 2003, 140, 255-266. [CrossRef]

9. Litrico, I. Strategy avenues for breeding plants for multispecies grasslands. In Grassland Science in Europe; Huguenin-Elie, O., Studer, B., Kölliker, R., Reheul, D., Probo, M., Barre, P., Feuerstein, U., Roldán-Ruiz, I., Mariotte, P., Hopkins, A., Eds.; European Grassland Federation EGF; Wageningen Academic Publishers: Wageningen, The Netherlands, 2019; Volume 24, pp. 27-35.

10. Litrico, I.; Violle, C. Diversity in Plant Breeding: A New Conceptual Framework. Trends Plant Sci. 2015, 20, 604-613. [CrossRef]

11. Sampoux, J.P.; Giraud, H.; Litrico, I. Which recurrent selection scheme to improve mixtures of crop species? Theoretical expectations. G3 Genes Genomes Genet. 2020, 10, 89-107. [CrossRef]

12. Annicchiarico, P.; Collins, R.P.; De Ron, A.M.; Firmat, C.; Litrico, I.; Hauggaard-Nielsen, H. Do we need specific breeding for legume-based mixtures. In Advances in Agronomy; Sparks, D.L., Ed.; Academic Press Ltd.: London, UK; Elsevier Science Ltd.: London, UK, 2019; Volume 157, pp. 141-215.

13. Charles, J.; Lehmann, J. Intérêt des mélanges de graminées et de légumineuses pour la production fourragère en Suisse. Fourrages 1989, 119, 311-320.

14. Rowe, D.E.; Brink, G.E. Heritabilities and genetic correlations of white clover clones grown in three environments. Crop Sci. 1993, 33, 1149-1152. [CrossRef]

15. Caradus, J.R.; Mackay, A.C.; Van Den Bosch, J.; Woodfield, D.R. Comparative evaluation of white clover cultivars in spaced plant and small mixed species plot trials. N. Z. J. Agric. Res. 1989, 32, 433-436. [CrossRef]

16. Dijkstra, J.; De Vos, A.L.F. The evaluation of selections of white clover (Trifolium repens L.) in monoculture and in mixture with grass. Euphytica 1972, 21, 432-449. [CrossRef]

17. Zannone, L.; Rotili, P.; Paoletti, R.; Scotti, C. Experimental studies of grass-legume associations. Agronomie 1986, 6, 931-940. [CrossRef]

18. Rotili, P.; Zannone, L.; Jacquars, P. Effects of association on the evaluation of lucerne populations. Ann. Amelior. Plant. 1976, 28, 139-145.

19. Maamouri, A.; Louarn, G.; Béguier, V.; Julier, B. Performance of lucerne genotypes for biomass production and nitrogen content differs in monoculture and in mixture with grasses and is partly predicted from traits recorded on isolated plants. Crop. Pasture Sci. 2017, 68, 942-951. [CrossRef]

20. Klein, T.; Holzkämper, A.; Calanca, P.; Fuhrer, J. Adaptation options under climate change for multifunctional agriculture: A simulation study for western Switzerland. Reg. Environ. Chang. 2014, 14, 167-184. [CrossRef]

21. Suter, D.; Rosenberg, E.; Frick, R. Standardmischungen für den Futterbau. Revision 2021-2024; Arbeitsgemeinschaft zur Förderung des Futterbaus (AGFF) \& Agroscope: Zurich, Switzerland, 2021.

22. R Core Team. R: A Language and Environment for Statistical Computing; R Foundation for Statistical Computing: Vienna, Austria, 2020.

23. Bates, D.; Maechler, M.; Bolker, B.; Walker, S. Fitting linear mixed-effects models using lme4. J. Stat. Softw. 2015, 67, 1-48. [CrossRef]

24. Falconer, D.S.; Mackay, T.F. Introduction to Quantitative Genetics; Longman Group Ltd.: Harlow, UK, 1996.

25. Fyfe, J.L.; Rogers, H.H. Effects of varying variety and spacing on yields and composition of mixtures of lucerne and tall fescue. J. Agric. Sci. 1965, 64, 351-359. [CrossRef]

26. Rumbaugh, M.D.; Pendery, B.M. Stability of forage yield of alfalfa clones grown with five associate species. Can. J. Plant Sci. 1991, 71, 453-459. [CrossRef]

27. Zannone, L.; Assemat, L.; Rotili, P.; Jacquard, P. An experimental study of intraspecific competition within several forage crops. Agronomie 1983, 3, 451-459. [CrossRef] 
28. Samac, D.A.; Rhodes, L.H.; Lamp, W.O. Compendium of Alfalfa Diseases and Pests; Am Phytopath Society: St. Paul, MN, USA, 2016. [CrossRef]

29. Fasoula, D.A.; Fasoula, V.A. Competitive Ability and Plant Breeding. Plant Breed. Rev. 1997, 14, 89-138.

30. Chamblee, D.S.; Collins, M. Relationships with other species in a mixture. In Alfalfa and Alfalfa Improvement; Hanson, A.A., Barnes, D.K., Hill, R.R.J., Eds.; American Society of Agronomy (ASA): Madison, WI, USA, 1988; Volume 29, pp. $439-461$.

31. Maamouri, A.; Louarn, G.; Gastal, F.; Béguier, V.; Julier, B. Effects of lucerne genotype on morphology, biomass production and nitrogen content of lucerne and tall fescue in mixed pastures. Crop. Pasture Sci. 2015, 66, 192-204. [CrossRef] 